Resumo

O presente artigo pretende refletir sobre o processo de constituição subjetiva do bebê prematuro internado em UTI neonatal, seus impasses e possibilidades de superação da condição de organismo a sujeito, destacando as implicacões do não reconbecimento primordial na prematuridade bem como a importancia do outro no estabelecimento dos endereçamentos desenvolvidos entre bebê, mãe e equipe de saúde.

Descritores: constituição subjetiva; sujeito; prematuridade; UTI neonatal; endereçamento.

\section{"SÃO BEBÊS \\ OU MIOMAS?" \\ IMPLICAÇÕES DO NÃO \\ RECONHECIMENTO PRIMORDIAL NA \\ CONSTITUIÇÃO SUBJETIVA'}

Cynthia Marden Torres

Maria de Fátima Vilar de Melo

DOl: http//dx.doi.org/10.11606/issn. 1981-1624.v21i1p30-44.

( )

presente trabalho pretende refletir sobre dificuldades concernentes ao reconhecimento primordial materno que podem ocorrer na prematuridade bem como suas implicações na constituição do sujeito. Tal objetivo partiu de atendimentos realizados pela primeira autora a bebês prematuros e suas mães bem como de observações à equipe multiprofissional da UTI-neonatal do Hospital Universitário Lauro Wanderley, em João Pessoa, Paraíba, quando participou das atividades clínicas do Grupo de Estudos, Pesquisa e Extensão em Psicanálise e Pediatria (GEPEPPE), coordenado pela psicanalista Dra. Telma Queiroz.

- Psicóloga. Doutoranda em Psicologia Clínica pela Universidade Católica de Pernambuco (UNICAP), Recife, PE, Brasil.

- Professora do Curso de Psicologia e do Programa de Pós-Graduação em Ciências da Linguagem da Universidade Católica de Pernambuco (UNICAP), Recife, PE, Brasil. 
A partir dos trabalhos de Bergès e Balbo (2002), Crespin (2004), Frej (2003) e Queiroz (2005), apresentamos uma tentativa de pensar um caso clínico para, assim, tentar demonstrar a constituição do sujeito humano, levando em consideração seu movimento intrínseco (Frej, 2003). No que se refere ao bebê prematuro, os fatores que elevam o organismo, tomado em sua imediatez, à condição de sujeito parecem ser mais difíceis do que em um bebê nascido a termo. Diante disso, as intervenções pela palavra dirigidas ao bebê são muito importantes nesse momento precoce da vida para solucionar esses possíveis impasses em direção ao processo de constituição subjetiva e o estabelecimento dos endereçamentos nas suas relações com o outro que cuida dele.

Bergès e Balbo (2002), ao explicarem essas interações da mãe com o bebê, apresentam a noção de transitivismo. Uma mãe, quando transitiva, faz uma hipótese de uma demanda no filho, supondo que ele articulará essa demanda ao seu desejo. Porém, na prematuridade, quando aquela se encontra mais preocupada com o funcionamento orgânico do filho, parece ficar impossibilitada de transitivar e, caso não haja essa suposição no bebê, o endereçamento não poderá acontecer. Isso tende a desencadear uma dificuldade também de ela poder reconhecer o filho como seu, por meio da identificação de características físicas e da atribuição de desejos, inserindo-o, assim, na linhagem familiar no primeiro encontro.

Crespin (2004) nomeia as reflexões descritas como "reconhecimento primordial" e acrescenta que o anúncio de doença ou um nascimento prematuro, por exemplo, podem ocasionar uma catástrofe subjetiva na mãe, um desinvestimento dela no bebê real e uma dificuldade de fazer o luto pelo bebê esperado. Assim, fatores de risco existentes em torno do nascimento tendem a aumentar o espaço entre o bebê imaginário e real, impossibilitando esse processo de reconhecimento inicial. Um superinvestimento também pode ocorrer com o mesmo sentido.

No que concerne ao caso trabalhado neste artigo, trata-se de um casal de gêmeos nascidos prematuramente, cuja mãe, da gravidez ao nascimento, confundia os filhos com os miomas que possuía e dos quais fazia tratamento.

Assim, interrogamo-nos a respeito de como ocorre o movimento de ultrapassagem do não reconhecimento primordial dessas crianças em direção ao processo de vinculação afetiva entre elas e sua mãe. Como ocorrem as modificações na dinâmica psíquica que leva à 
ultrapassagem de organismo para ocupar o lugar de sujeito?

Essa interrogação será trabalhada à luz da aufhebung freudiana, que consiste em uma importante ferramenta de análise, uma vez que explica o movimento intrínseco de criação de novos espaços psíquicos em direção ao estabelecimento da relação da mãe com seus bebês, segundo a definição de Frej (2003).

\section{Apresentação do caso}

Ana Larissa e José Vítor (nomes fictícios) são bebês que nasceram prematuros, com idade gestacional de 26 semanas: a menina pesando $690 \mathrm{~g}$, e o menino, $1 \mathrm{~kg}$. A mãe, que nomeamos de "Roberta", 40 anos, é companheira de "Bruno" - 24 anos - e tiveram seus primeiros filhos. Durante toda a gravidez até o nascimento, Roberta confundia os bebês com os miomas que possuía e dos quais fazia tratamento.

Como tinha os miomas, a mãe achava que não poderia engravidar. Tinha sangramentos constantes e já estava em tratamento há dois anos. Sua gestação foi difícil por causa da idade e corria o risco de o parto ser prematuro. Durante a gravidez, não enjoava nem sentia “desejos de grávida". Ao saber da notícia de que esperava um filho, ficou surpresa, chocada. Achou esquisito porque a barriga estava aumentando. O desconhecimento da gravidez e a estranheza diante dos sinais característicos que ela apresentou, quando associados à ênfase na doença que possuía, apontavam para dificuldades. Descobriu a gestação no segundo mês e fez exames por causa dos miomas, pois não acreditou que estaria grávida. No entanto, a ultrassonografia lhe mostrava dois filhos, mas Roberta dizia que já sabia que a gestação seria interrompida. Ela teria essa certeza por causa dos miomas com os quais os filhos eram confundidos? Ela esperava pelos miomas? Interrogamos aqui se essa certeza vem de seu desejo ou de seus medos de uma interrupção na gravidez.

No nascimento das crianças, ela sentia dores no "pé da barriga", mas não sabia que eram as contrações. Ela disse que já se encontrava internada no hospital por causa dos miomas e, quando foi ao banheiro urinar, o pé de um deles havia saído, e ela chamou a médica. As dores que sentiu pareciam apontar para a possível confusão que aparentava haver na representação psíquica dessa mãe entre os miomas e a gravidez. Roberta estava na maternidade fazia 16 dias por ter sangramentos, e a gravidez, segundo ela, seria interrompida a qualquer momento.

Crespin (2004) fala de um estado, o qual ela denominou de "sofrimento primordial”, que aponta, em sua origem, para o fato da dependência absoluta que tem o bebê humano do outro que cuida dele. Assim, sua vida só pode ser garantida por meio de 
uma ajuda exterior. Após o nascimento, o estado de prematuridade do recém-nascido leva-o a depender do outro para tudo. Diante disso, o personagem materno torna-se muito importante. Essa questão já se encontra presente na obra de Freud desde os seus primórdios. No "Projeto para uma psicologia científica" (1895/1950), Freud diz que a importância do outro ou do próximo prestativo para o ser humano está no fato de ser o portador do desejo de sobrevivência do recém-nascido, porque a criança, ao nascer, acha-se num estado de desamparo, dependendo inteiramente do outro para sobreviver (Frej, 2003).

Frej (2003), ao acompanhar o pensamento freudiano, destaca que o organismo humano é incapaz de executar a ação específica que o reconduz ao estabelecimento de seu equilíbrio. Assim, a pessoa atenta ao estado do bebê realiza a ação específica pelo aporte de uma ajuda estrangeira (fremde hilfe) durante os cuidados a ele realizados. Trata-se, segundo a autora (Frej, 2005), de um momento crucial, no qual o organismo é metamorfoseado em ser humano, e essa metamorfose parece acontecer a partir do momento em que o que antes seria apenas descarga das quantidades de excitação via reflexos do bebê passaria a ter a função secundária de uma relação com o outro a partir dos sentidos que este atribui às expressões da criança.

No entanto, o que acontece quando esse próximo prestativo, o semelhante, tal como Freud (1895/1950) denominou, não possui a qualidade de também ser prestativo, não possuindo o desejo de sobrevivência do bebê, como no caso em análise?

No início, já observávamos sinais de dificuldades, entraves ao processo de humanização e de inserção dessas crianças na linhagem familiar. Até então, o que se observa é que os lugares que esses bebês se encontravam eram de miomas. Depois do nascimento, o encontro entre a mãe e os bebês foi difícil, pois ela não conseguia pegá-los no braço, muito menos acalentá-los ou assumir a função desse outro que presta cuidados aos recém-nascidos, tal como refere o pai da psicanálise.

No primeiro dia em que viu os filhos na UTI-neonatal, por exemplo, Roberta não aguentou ficar muito tempo com eles e foi embora para o seu quarto. Sobre essa dificuldade, dizia não se sentir ainda preparada para tocá-los, e seus filhos eram vistos por ela como "sujinhos". Talvez, a situação de encontrar na realidade bebês que ela já não esperava, acrescido ao fato do nascimento prematuro, tenha acentuado ainda mais as dificuldades existentes em Roberta concernentes à sua maternidade. 
Para Crespin (2004), o reconhecimento primordial entre mãe e filho, nesse primeiro momento, tão importante para o estabelecimento dos laços, também estava em risco, pois ainda não se havia estabelecido. A autora afirma o quão importante ele é nesse período quando o personagem materno consegue, por meio da identificação, atribuir desejos e reconhecer, no seu bebê, características físicas e/ou psicológicas que o relacione à família. Dessa forma, permite que se produza o encontro entre o bebê imaginário e o real, para que a mãe possa endereçar-se ao seu filho.

Geralmente, desde o nascimento, ocorre o encontro, e, por um ato de projeção, a mãe se identifica com a criança. No caso em tela, percebemos que existe uma dificuldade da mãe em ver as crianças e, por um bom tempo, ela se recusou a pegar os filhos no colo, o que aponta para um risco ao estabelecimento de uma boa qualidade do laço mãe-bebê bem como riscos para o processo de subjetivação.

A partir da observação dessa dificuldade inicial, deparamo-nos, mais claramente, com o que seria uma tentativa de pensar sobre o movimento intrínseco à constituição do sujeito humano. No que concerne ao bebê nascido prematuramente, as condições que promovem uma ultrapassagem do organismo ao sujeito parecem ser mais complexas do que em um bebê nascido a termo, segundo apontou Frej, Torres e Vilar de Melo (2011). Diante de tal aspecto, a imaturidade fisiológica do organismo do bebê prematuro e seus desdobramentos, bem como a condição de sua internação em UTI-neonatal, pode produzir obstáculos ao advento do sujeito, pois a atenção dos pais e da equipe de saúde tende a direcionar, muitas vezes, ao organismo do bebê, sempre passível de cuidados intensivos e, muitas vezes, urgentes. Logo, as intervenções pela palavra endereçadas ao bebê apresentam-se, nesse momento precoce da vida, como possibilidades para lidar com os impasses que advierem no estabelecimento das suas relações com o outro que cuida dele (Torres, 2009).

Ainda no que concerne à questão da prematuridade, recorremos ao que Crespin (2004) afirma sobre o potencial que têm os fatores de risco ligados a doenças, a deficiências e a más formações em torno do nascimento em aumentar a distância entre o bebê imaginário e o bebê real, ingredientes que dificultam o processo de reconhecimento primordial. No entanto, na história de Roberta e seus bebês, um rumo diferente ocorreu: ela dizia que nunca pensou que seria mãe e relatou que a vinda dos bebês aconteceu em um momento que ela e o companheiro tinham outros planos. 
Se, por um lado, podemos supor com base no que afirmamos que a prematuridade de seus bebês tenha reforçado seus medos e conflitos, por outro lado, é provável que, em função dessa prematuridade, a mãe pôde contar com a intervenção da equipe hospitalar, que lhe ofereceu o suporte necessário para que ela viesse assumir o seu lugar e, por conseguinte, a maternagem dos seus filhos. Assim, interrogamos: como se deu o movimento de ultrapassagem do não reconhecimento primordial dessas crianças em direção ao processo de vinculação afetiva entre a mãe e os bebês? Como ocorrem as modificações na dinâmica psíquica que leva a suplantar a condição de organismo para ocupar o lugar de sujeito?

Para a leitura desse caso, recorreremos, sobremaneira, à noção freudiana de aufhebung, demonstrada por Frej (2003) em sua tese de Doutorado, que consiste em uma importante ferramenta de análise do ponto de vista da clínica e da técnica para explicar como ocorreu o estabelecimento da relação da mãe com seus bebês.

"Aufhebung" é um termo da língua alemã encontrado por Frej (2003), ao longo da obra de Freud, que abriga significados díspares: negar, conservar e ultrapassar. A melhor tradução para o português desse termo, segundo Menezes (1985) citado por Frej (2003, 2007), é "suprassunção". Partindo dessa tradução, a autora afirma que esse termo possibilita a compreensão do movimento inerente ao psiquismo e tange à circulação da energia e de sua passagem pelo organismo. Esse movimento encontra-se presente desde o momento em que prevalece o inorgânico, que será suprassumido e se desdobrará em órgão, organismo, corpo, situados numa sociedade e numa cultura.

A autora conclui que, no texto de Freud, o termo "Aufhebung" institui fronteira, conservando a continuação dos espaços demarcados, pois consiste em um movimento que

por conter em si uma negação daquilo que, por ser negado, é conservado enquanto o mesmo e enquanto outro. O que na Aufhebung freudiana impulsiona o movimento é a ultrapassagem daquilo que continuou mesmo depois de a negação ter operado. É 'tornar-se o mesmo quando já se é outro' (Frej, 2007, p. 155).

Para pensarmos sobre os últimos questionamentos levantados acerca das mudanças psíquicas na relação da mãe com os bebês, ilustremos, agora, com alguns fragmentos, situações ocorridas nos dias que se seguiram à internação deles. Assim, pela articulação da clínica psicanalítica de bebês, cuja "prática analítica se cumpre no 
campo da palavra" (Jerusalinsky, 2011, p. 16), com a noção de Aufhebung, enfocaremos a abordagem da equipe da UTI, no sentido de como esta colaborou com o estabelecimento dos endereçamentos e com o advento de mudanças na relação da mãe com os filhos.

Certo dia, Roberta estava tirando leite para os bebês no corredor e reclamou de um bloqueio na sua mente que impedia a descida do leite. Ela chegou, sozinha, à conclusão de que algo estava gerando um estado de tensão que bloqueava a saída do leite e que o seio estava doendo muito. Portanto, ela disse que "botou no subconsciente que queria secar o leite"; ela desistiu por causa da dor, e ninguém conseguia tocá-los, mas depois decidiu que alguém retirasse o leite. Sobre sua dificuldade, dizia: " $j a ́$ fir massagem, já aceitei a ordenha, já pedi remédio à médica. . . . Acho que botei na cabeça que queria secar o leite".

Amamentar ao seio, segundo Queiroz (2005), é a forma que mais se aproxima da continuidade intrauterina e ameniza a angústia do bebê, que vive seus primeiros dias de existência de maneira tão penosa. Os bebês, nesse caso, não foram amamentados e, por serem muito prematuros, ficaram muito tempo na incubadora e não podiam ser pegos no colo. Quando estiveram fora de risco, continuaram não sendo amamentados por causa da dificuldade da mãe.

Com base nessa afirmação da autora, pensaríamos em uma interrupção nessa continuidade mãe-bebê. Então, quais implicações isso poderia ter na constituição psíquica de uma criança nascida prematura? Talvez essa dificuldade esteja relacionada a questões concernentes ao desejo dessa mãe que repercutiram na gravidez dos bebês e nos primeiros meses que se seguiram ao nascimento. A amamentação é uma das primeiras maneiras de o bebê se tornar um sujeito, pois até mesmo o processo de lactação a ele se destina e faz surgir o leite no seio da mãe. Interessante que a mãe dos bebês concluiu que algo no seu psiquismo bloqueava esse processo natural. O que a estaria bloqueando?

Nesse sentido, Queiroz (2005) aponta fatores que levam a uma inibição da lactação; dentre eles, o pouco 
contato da mãe e a demora em amamentar. A ruptura, que já ocorre no nascimento entre mãe e filho, se intensifica em bebês prematuros como eles, que não podem, após o nascimento, entrar em contato com algumas sensações conhecidas quando estavam no útero. Assim, para que esses sentidos se manifestem, é necessário o contato físico com a mãe, que, nos primeiros dias dessas crianças, foi interrompido por causa da prematuridade extrema e do baixo peso ao nascer.

Roberta se via em um conflito com o que estava acontecendo na realidade: a falta de leite e a angústia de ter que amamentar seus bebês. Essa dificuldade a acompanhou durante boa parte da internação. Com o passar dos dias, a mãe estava mais acostumada e animada com eles; continuou a falar sobre suas dificuldades de aleitamento e passou a visitá-los com frequência. Assim percebemos que o choque inicial ao reconhecer seus bebês passou a uma melhora na relação no decorrer dos dias.

Apesar de entendermos, segundo Freud (1895/1950), que a amamentação dá uma sensação de continuidade com a vida intrauterina, nesse caso, parece não haver ainda corpo da mãe e corpo da criança, como se o corpo de um continuasse no corpo do outro, e o órgão de um fizesse funcionar o do outro. Isso evoca o que Frej (2003, 2005) fala sobre o mèrenfant e a questão da massa, ou seja, mãe e bebê como uma unidade indiferenciada.

Assim sendo, como pensar na relação entre a mãe e os bebês e na descida do leite? A princípio, o relacionamento entre eles parecia muito difícil. Porém, graças ao apoio recebido pela equipe da UTI, a maternagem foi se instalando ao longo do tempo, fator que deve ter concorrido favoravelmente para a descida do leite.

Queiroz (2005) explica que amamentar, do ponto de vista metapsicológico, é o correspondente à experiência de satisfação da pulsão oral, estando esta, para Freud (1895/1950), na origem da constituição do aparelho psíquico e do pensamento da criança. $\mathrm{O}$ dar à criança o seio seria o constituinte da ação específica que faz parte da experiência de satisfação. Podemos articular essa temática com o que Frej (2003) se refere à massa indiferenciada 
(mèrenfant) e à noção de Aufhebung em operação nesse momento.

No ponto de vista de Frej (2003, 2005), a indiferenciação da massa concerne a um momento ficcional que antecede aquele que, para Freud, constitui o momento da experiência de satisfação e dá suporte ao surgimento do ser humano. Essa experiência é correlativa ao surgimento de um corte na massa indiferenciada mãe e bebê, consistindo uma primeira fronteira entre aquilo que constitui o organismo e o que institui o ser humano. Esse corte acontece por meio da palavra, que a autora considera como ajuda estrangeira (fremde Hilfe).

No exemplo do caso em tela, também podemos observar esses movimentos de passagem que acontecem na dinâmica relacional da mãe com os seus bebês, que, no decorrer do tempo da internação em UTI, apresentaram mudanças psíquicas significativas acerca das superações de algumas dificuldades de conferir um lugar no psiquismo materno às crianças, cuja descrição segue:

Certa manhã, Roberta já conseguia pegá-los ao colo e conversava com a menina. Observamos que, em bebês em situação de internação hospitalar, a doença parece estar sempre presente de maneira insistente na história precoce deles e nos cuidados que lhes são dispensados. Porém, o próprio endereçamento da palavra aos bebês, por exemplo, já se ascende do campo da organicidade à hipótese de um pedido. A mãe já destaca do corpo dos bebês uma necessidade, atribuindo-lhes uma palavra, e essa atribuição não se limita ao campo das necessidades vitais.

Outro aspecto bastante importante concerne à equipe de saúde da UTI-neonatal que atendeu a esse caso. Destacamos a atuação das técnicas de enfermagem nos momentos de procedimento. Em muitos destes, o bebê José Vítor apresentou sinais de apatia, pois não conseguia, no início, reagir a qualquer estímulo ou fala dos profissionais que cuidavam dele.

Um dia, a técnica de enfermagem chegou para coletar sangue e falou com o menino: "Não sei seu nome, viu, moco, mas vou ter que fazer malvadeza aqui", referindo-se à coleta de sangue dele. Interessante a sua fala, que confere uma existência a esse bebê e pontua aqui a importância que ela dá ao nome para poder endereçar-se a ele, um sinal de aposta no sujeito. Depois, continuou a conversa - "Você é um rapaz?" - e ficou procurando a veia no seu bracinho. Ele fez careta, não chorou. Parecia apático quando a enfermeira o furou mais uma vez. Em seguida, explicou ao bebê - "Vamos fazer o seguinte: vou furar o seu pé" - e com um tubinho coletou o sangue, pois estava difícil achar uma veia no braço. Vítor continuava indiferente aos procedimentos, o que sinalizou que algo não estava indo bem com ele. Percebemos que as pessoas que cuidavam desse bebê normalmente endereçavam-lhe as palavras acerca das coisas que aconteciam ao seu 
redor e expressavam em seus procedimentos a preocupação em causar dor ao furar uma criança tão frágil.

Por conta da dificuldade de se coletar o sangue de um bebê tão pequeno e por ser o novato da UTI-neonatal, a técnica de enfermagem falou para ele, carinhosa: "Menino, facilite as coisas. ...V Você chegon agora, tá?". Um ponto interessante diz respeito à insistência dessa equipe no sentido de continuar endereçando palavras ao bebê, como uma tentativa de apostar em um sujeito e na sua possibilidade de recuperação. Poderíamos pensar nessa profissional que atende ao menino nesse caso como o "próximo prestativo" denominado por Freud (1895/1950), pois ela sinalizava, em seus cuidados, uma aposta e um desejo de sobrevivência pela criança, que, com o passar do tempo, conseguiu interagir com quem conversasse com ele, surpreendendo, dessa forma, os pais, com os avanços dele. Fato correlato aconteceu com Ana Larissa.

Logo, podemos pensar, a partir dos exemplos das falas destacadas, sobre como ocorreu o endereçamento da técnica para com a criança e desta para com a profissional: observamos uma pessoa atenta aos cuidados e necessidades urgentes do bebê a quem dirige a palavra, apresentando-lhe os primeiros significantes. E, por outro lado, observamos um bebê apático aos toques do outro, sem reagir à dor de uma agulha e a uma palavra carinhosa de alguém. Bergés e Balbo (2002) apontaram que, normalmente, 
o endereçamento se faz em duas direções, de um sujeito para outro, e aqui, nesse caso, isso parecia não acontecer inicialmente. No entanto, a insistência por parte da equipe, mesmo diante da fragilidade e da indiferença do bebê, pode ser um dos fatores motivadores de impulsioná-lo em direção à vida e ao outro, de quem ele ainda está indiferenciado.

Com esses fragmentos do caso, articulamos também, a partir de Frej (2003), o estabelecimento do endereçamento com a operação de Aufhebung pela palavra como impulsionadora desse movimento, que cria novos lugares psíquicos. Essa autora (2003, 2005) argumenta que a palavra constitui uma ajuda estrangeira em relação à mãe e ao bebê, o que dá início a esse movimento de operação. Talvez aqui, a partir desse suporte das palavras endereçadas pela técnica de enfermagem ao bebê, possam constituir-se nele espaços psíquicos diferenciados, promovendo a transformação do organismo em corpo.

Assim, observamos, com a história de Roberta e seus bebês, a sequência de um movimento intrínseco à relação em direção à criação de lugares psíquicos novos, rumo ao sujeito em constituição: antes do nascimento, confundidos com miomas, não reconhecidos; depois, promovidos a filhos de Roberta, assim, por ela reconhecidos.

Quais aspectos podem ter levado a essas mudanças na mãe bem como na relação dela com seus bebês? Levantamos a hipótese de que algo referente às intervenções pela palavra e ao investimento atravessado pelos cuidados dos membros da equipe de profissionais da UTI tenham circulado nessa história, e esse suporte pode ter despertado mudanças na mãe em direção ao desejo. A palavra, tal como Frej (2003) aponta, pode ter se apresentado enquanto ajuda estrangeira (fremde Hilfe), ou seja, trazendo um corte impulsionador desses novos movimentos de criação de lugares psíquicos, no sentido de uma ultrapassagem da dificuldade do endereçamento a uma possibilidade de essa mãe despontar para uma relação com seus bebês.

Além disso, o maior envolvimento e participação de Roberta, decorridos alguns meses da internação das 
crianças, foi importante. Suas palavras, por exemplo, demonstram certa animação quando ela nos diz: "Você viu como eles estão bem, né?! Tão gostoso pegar neles. Mamãe vai botar tanto amor nesses pequenos!". Apesar de serem bebês prematuros e em condições frágeis, tanto o pai como a mãe se deram conta de que algo havia além do corpo frágil da prematuridade, evidenciando essa condição de ultrapassagem da condição de puro organismo em direção a um lugar de sujeito, da carência inicial de endereçamento ao endereçamento.

\section{À guisa de conclusão}

Esse caso levou-nos a tecer algumas considerações acerca do processo de constituição de sujeito e das condições de superação das dificuldades que podem gerar obstáculos a esse processo.

A partir da atuação da equipe multiprofissional da UTI-neonatal, podemos identificar algumas modificações na dinâmica psíquica da mãe com seus bebês que possibilitaram a superação da condição de organismo prematuro a uma aposta nos sujeitos José Vítor e Ana Larissa, impulsionando o estabelecimento dos endereçamentos na relação da mãe com seus filhos.

Malgrado as dificuldades iniciais de endereçamento às crianças por parte da mãe, a insistência por parte da equipe em relação ao bebê José Vítor, por exemplo, pode ter sido um dos fatores que impulsionaram o bebê em direção à vida. A técnica de enfermagem, mesmo diante da fragilidade do bebê e da indiferença deste, continuou a endereçar-se a ele, com palavras e gestos carinhosos. Fundamentadas em Frej (2003), destacamos a importância dessas ações, uma vez que o aporte da palavra dá início ao movimento de criação de lugares psíquicos. Talvez aqui, a partir desse suporte das palavras endereçadas da enfermeira ao bebê, puderam-se constituir nele espaços psíquicos diferenciados, dando impulso a mudanças psíquicas na relação com os bebês. 
Mesmo com os momentos de tensão vivenciados pela mãe e pelas crianças, no decorrer da internação até a alta, observamos que algo da relação deles, que era inicialmente difícil, harmonizou-se. Roberta passou a lidar melhor com a situação, com seu bom humor e otimismo. A depressão inicial, que a paralisara, tomou outro rumo, e ela se tornou uma mãe participante nos cuidados aos bebês, além de ser muito querida por todos da equipe e pelas mães internadas, tendo em vista sua facilidade de relacionar-se com as pessoas. Seus bebês puderam passar pelas dificuldades contando com ela e com a equipe, o que exerceu um papel muito importante na restauração do vínculo entre eles.

Assim, percebemos o quanto a clínica psicanalítica de recém-nascidos tem evidenciado situações da ordem do inusitado. A eficácia percebida nas intervenções feitas pela palavra parece provocar efeitos rápidos nos bebês, que expressam o seu sofrimento pela linguagem dos sintomas no organismo, nem sempre explicáveis. Essas constatações observadas no contato com os bebês prematuros insistem em apontar para algo muitas vezes enigmático, que escapa ao âmbito da ciência, despertando, assim, uma gama de situações observáveis, mas imprevisíveis, que dizem respeito a outra ordem, regida pelo inconsciente, no surgimento do sujeito em constituição no bebê.

Uma compreensão mais profunda de como se vai construindo a relação entre a mãe e o bebê prematuro na UTI-neonatal precisa levar em conta a influência do desejo nas intervenções da equipe de saúde da UTI-neonatal e nas direções que essa criança venha a tomar, quer seja para sua recuperação ou não. Esse entendimento é essencial para as práticas de intervenção por parte dos profissionais que atuam em clínicas neonatais, pediátricas e ambulatoriais, para que possam lidar melhor com situações que envolvam o bebê. É preciso que este seja visto como um sujeito em constituição, além da problemática orgânica que o acometeu, pois se houver risco de morte, os riscos subjetivos também são enormes.

Assim, concluímos com uma das falas de Roberta, que nos disse sorrindo: "São perfeitos, têm tudo, os dedinhos 
todos certinhos... Como vai ser para comprar um sapatinho pra eles?", deixando evidente, aqui, a promoção de lugares: de miomas aos bebês Ana Larissa e José Vítor, agora reconhecidos como seus filhos.

"ARE THEY BABIES OR MYOMAS?” IMPLICATIONS OF THE PRIMORDIAL NONRECOGNITION IN THE SUBJECTIVE CONSTITUTION

\section{Abstract}

This article aims to reflect on the process of subjective constitution of preterm babies hospitalized in neonatal ICU, their impasses, and the possibilities of overcoming the condition of organism to subject, highlighting the implications of the primordial nonrecognition in prematurity, as well as the importance of the other in the establishment of the interactions developed among baby, mother, and medical staff.

Index terms: subjective constitution; subject; prematurity; neonatal ICU; interactions.

“¿SON BEBÉS O MIOMAS?” IMPLICACIONES DEL NO RECONOCIMIENTO PRIMORDIAL EN LA CONSTITUCIÓN SUBJETIVA

\section{RESUMEN}

Este articulo propone a reflexionar acerca del proceso de constitución subjetiva del bebé prematuro internado en la UCI neonatal, sus consecuencias y posibilidades de superación de la condición de organismo a sujeto, resaltando las consecuencias del no reconocimiento primordial acerca de la prematuridad, así como la importancia del "otro" en el establecimiento de los direccionamientos desarrollados entre bebé, madre y equipo médico.

Palabras clave: constitución subjetiva; sujeto; prematuridad; UCI neonatal; direccionamientos.

\section{REFERÊNCIAS}

Bergès, J., \& Balbo, G. (2002). Jogo de posiçōes da mãe e da criança: Ensaios sobre o transitivismo. Porto Alegre, RS: CMC.

Crespin, G. (2004). A clínica precoce: O nascimento do humano. São Paulo, SP: Casa do Psicólogo.

Frej, N. Z. (2003). Le don du nom et son empêchement: Au sujet des enfants de rue au Brésil. (Tese de Doutorado), Universidade Paris 13, Paris.

Frej, N. Z. (2005). Ao longo do caminho tem uma pedra. Trabalho apresentado na Reunião Lacano-Americana de Psicanálise, Florianópolis, SC. (inédito) 
Frej, N. Z. (2007). Com um grande X. In A. Costa \& D. Rinaldi (Orgs.). Escrita e psicanálise (pp. 147-156). Rio de Janeiro, RJ: Companhia de Freud.

Frej, N. Z., Torres, C. M., \& Melo, M. F. V. (2011). Do organismo ao sujeito: A ultrapassagem da imediatez do corpo do bebê prematuro à luz da aufhebung freudiana. In M. C. Laznik \& D. Cohen (Orgs.), O bebêe eseus intérpretes: Clínica e pesquisa (pp. 145-152). São Paulo, SP: Instituto Langage.

Freud, S. (1950). Projeto para uma psicologia científica. In S. Freud, Freud online. Recuperado de http://www.freudonline.com.br/livros/volume-01/vol-i-16projeto-para-uma-psicologia-cientifica-1950-1895/. (Trabalho original publicado em 1895)

Jerusalinsky, A. (2011). Para entender a criança: Chaves psicanaliticas. São Paulo, SP: Instituto Langage.

Queiroz, T. C. N. (2005). Do desmame ao sujeito. São Paulo, SP: Casa do Psicólogo.

Torres, C. M. (2009). Incidências do desejo materno nas possibilidades de recuperação do bebê prematuro. (Dissertação de Mestrado), Programa de Pós-graduação em Psicologia Clínica, Universidade Católica de Pernambuco, Recife, PE.

\section{NOTA}

1. Este artigo tem como ponto de partida um trabalho apresentado no Séminaire transdisciplinaire sur le bébé: L'émergence du sujet et développement du bébé, em julho de 2013 em Paris, cuja elaboração contou com a participação efetiva de Nanette Zmeri Frej. No entanto, no período inicial em que o trabalho apresentado foi transformado em artigo, ela adoeceu gravemente, vindo a falecer em janeiro do corrente ano. Não obstante, suas ideias, mesmo suas palavras, marcaram de modo fecundo a produçáo deste texto. Assim, este artigo representa um agradecimento (in memorian) e uma homenagem que lhe prestamos.

cynthia.marden@gmail.com

Rua Elísio Jorge de Brito, 148/202

58037-685 - João Pessoa - PB - Brasil.

mfvmelo@uol.com.br

Rua Guilherme Pinto, 50/1001

52011210 - Recife - PE - Brasil.

Recebido em junho/2015. Aceito em dezembro/2015.

44 Estilos clin., São Paulo, v. 21, n. 1, jan./abr. 2016, 30-44. 